\title{
Bimatoprost $0.01 \%$ vs bimatoprost 0.03\%: a 12-month prospective trial of clinical and in vivo confocal microscopy in glaucoma patients
}

M Figus ${ }^{1}$, M Nardi' , P Piaggi ${ }^{2}$, M Sartini ${ }^{1}$, G Guidi ${ }^{1}$, L Martini $^{1}$ and S Lazzeri ${ }^{1}$

This article has been corrected since Advance Online Publication and a corrigendum is also printed in this issue.

${ }^{1}$ Ophthalmology Unit, Department of Surgical, Medical and Molecular Pathology, and Critical Area, University of Pisa, Pisa, Italy

${ }^{2}$ Department of Endocrinology and Metabolism, University of Pisa, Pisa, Italy

Correspondence: S Lazzeri, Ophthalmology Unit, Department of Surgical, Medical and Molecular Pathology, and Critical Area, University of Pisa, Via Paradisa, 2, Building 30/A, Oculistica Universitaria, 56100 Pisa, Italy.

Tel: +39 333 8845890;

Fax: +39050 997675 .

E-mail: stefano_lazzeri@ hotmail.it

Received: 10 June 2013 Accepted in revised form: 19 November 2013 Published online: 17 January 2014

This paper has been presented as a poster in the ARVO meeting, Seattle, USA, 2013

\begin{abstract}
Purpose To evaluate the safety of two commercially available formulations of bimatoprost eye drops: 0.03 and $0.01 \%$ ophthalmic solutions.

Methods This was a randomized, prospective, parallel-group, open-label, cohort study. A total of 60 glaucoma patients (60 eyes) under bimatoprost $\mathbf{0 . 0 3 \%}$ monotherapy since at least 1 year were enrolled. Selected patients were randomized to receive a single drop of bimatoprost $0.01 \%(n=30)$ or bimatoprost $0.03 \%(n=30)$ ophthalmic solutions for 12 months. Statistical analysis was performed using paired $t$-test and repeated measures ANOVA test.

Results Global clinical score (the sum of pruritus, stinging/burning, blurred vision, sticky eye sensation, eye dryness sensation, and foreign body sensation) significantly decreased in the bimatoprost $0.01 \%$ group from baseline $4.7 \pm 3.8$ to $2.9 \pm 2.3(P<0.001)$ and $2.5 \pm 2.0(P<0.001)$ at 6 -month and 12-month follow-ups, respectively. Comparison between groups showed differences at both follow-up visits ( $P=0.003$ and $P<0.001$, respectively). In vivo confocal microscopy revealed a significant increase in goblet cell density in the bimatoprost $0.01 \%$ group compared with the bimatoprost $0.03 \%$ group $(P<0.001$ at both follow-up visits). All functional parameters and conjunctival hyperemia improved in the bimatoprost $0.01 \%$ group at each follow-up visit $(P<0.05)$ and in comparison with bimatoprost $0.03 \%(P<0.05)$.
\end{abstract}

Conclusion The results of this trial suggest that bimatoprost $0.01 \%$ eye drops seem to decrease the ocular discomfort with respect to bimatoprost $\mathbf{0 . 0 3 \%}$ eye drops.

Eye (2014) 28, 422-429; doi:10.1038/eye.2013.304; published online 17 January 2014

Keywords: bimatoprost $0.01 \%$ eye drop; bimatoprost $0.03 \%$ ophthalmic solution; in vivo confocal microscopy; goblet cell density; BAK; ocular drug preservatives

\section{Introduction}

Glaucoma, a leading cause of irreversible visual loss with 60 million people worldwide being affected, ${ }^{1,2}$ is a progressive optic neuropathy characterized by degeneration of retinal ganglion cells and loss of the retinal nerve fiber layer associated with visual field loss. ${ }^{3,4}$ Several risk factors for progression of visual field loss have been identified, including abnormal baseline anticardiolipin antibody levels, older age, raised intraocular pressure (IOP), and female sex. ${ }^{5}$ Nevertheless, the only modifiable risk factor for the glaucoma progression is currently IOP. ${ }^{6}$ Therefore, the therapeutic goal for the prevention of visual field loss is the lowering of IOP. ${ }^{7}$

Over the past 15 years, the introduction of prostaglandin analogs changed the pharmacological management of glaucoma. Prostaglandin analogs, including latanoprost, bimatoprost, travoprost, and more recently tafluprost, administered once per day, are 
currently the most effective topical medications available for reducing $\mathrm{IOP}^{8}$ and recommended by European Glaucoma Society (2008) as the first-line treatment of glaucoma. ${ }^{9}$

Bimatoprost is an ethyl amide pro-drug derivative of the potent but not selective FP prostaglandin receptor agonist: 17-phenyl-trinor $\mathrm{PGF}_{2 \alpha}{ }^{10,11}$ Bimatoprost $0.03 \%$ ophthalmic solution (Lumigan; Allergan, Inc., Irvine, CA, USA) was introduced into ophthalmic practice in $2001 .{ }^{12}$ It has been demonstrated to be safe and effective in lowering IOP by $6.5-8.9 \mathrm{~mm} \mathrm{Hg}$ over the long term in glaucoma and ocular hypertension (OHT) ${ }^{13-17}$ However, bimatoprost $0.03 \%$ eye drop is burdened with some side effects. Conjunctival congestion, which is believed to result from nitric oxide-mediated vasodilatation in the conjunctiva, ${ }^{18,19}$ is the most frequent adverse effect, accounting for discontinuation of therapy in about $3 \%$ of patients. ${ }^{20}$ Also, increased ocular discomfort is typically associated with long-term use of prostaglandin analogs. ${ }^{21}$

A new formulation of bimatoprost with a lower concentration of the drug (0.01\%; Lumigan, Allergan, Inc.) has been developed. The goal was to maintain the IOPlowering efficacy achieved with $0.03 \%$ formulation while reducing the overall safety profile, particularly in improving ocular surface tolerability. Compared with the original formulation $(0.005 \%)$, the new formulation has a 4 -fold increase in the amount of benzalkonium chloride (BAK) (0.020\%). ${ }^{22}$ Therefore, the strategy was to reduce the concentration of the drug and increase the concentration of BAK, a quaternary ammonium salt with a high power germicidal and disinfectant, that can increase the corneal penetration ${ }^{23}$ and intraocular bioavailability of topically applied medications. This characteristic can be explained by a loss of tight junctions in the corneal epithelium, favoring corneal penetration. ${ }^{24}$ However, the presence of BAK in ophthalmic solutions may also cause ocular toxicity, as demonstrated by numerous in vitro and in vivo studies. ${ }^{25-28}$ Thus, the higher BAK concentration of the new bimatoprost formulation may have implications for drug safety and tolerability.

Kats et $a l^{12}$ have recently demonstrated that bimatoprost $0.01 \%$ is equivalent to bimatoprost $0.03 \%$ in lowering IOP throughout 12 months of treatment with less associated incidence of side effects such as conjuctival hyperemia. However, clinical symptoms and in vivo confocal microscopy (IVCM) findings have not been investigated.

The present study aimed to evaluate the safety of the new bimatoprost $0.01 \%$ formulation, comparing subjective ocular symptoms and clinical and IVCM features in glaucoma patients treated with bimatoprost $0.03 \%$ since at least 1 year and randomized to receive bimatoprost $0.01 \%$ or bimatoprost $0.03 \%$ throughout a 12-month follow-up period. The Glaucoma Unit in Pisa University is a 'second step access', as most patients are already under local therapy; so, for us it was more useful to investigate patients already under prostaglandin analog eye drop treatment. In fact, this clinical trial aims to understand whether switching from bimatoprost $0.03 \%$ to bimatoprost $0.01 \%$ is effective and beneficial to these patients, as they account for the majority of cases in our Glaucoma Unit.

\section{Material and methods}

\section{Statement of ethics and subjects}

Data from a prospective clinical study were analyzed. All the patients were examined at The Glaucoma Unit of Pisa University (Italy), from March 2011 to September 2012. The tenets of the Code of Ethics of the World Medical Association (Declaration of Helsinki) for experiments involving humans were followed, and the Pisa University Hospital medical ethics committee approved the study. All patients signed an informed consent form after explanation of the nature and the possible consequences of the study. Industry involvement was absent in the design, conduct, and analysis of the study.

\section{Patients, clinical examination, and treatment}

This was a randomized, prospective, parallel-group, open-label clinical study evaluating clinical symptoms and signs, anterior segment photography, and IVCM features.

Subjects enrolled in this clinical study were 60 (60 eyes) consecutive open angle glaucoma (POAG), pseudoexfoliation glaucoma, and pigmentary glaucoma in monotherapy with bimatoprost $0.03 \%$ eye drops since at least 1 year.

Patient eligibility was evaluated at a screening visit and confirmed at a baseline few days later. Each patient underwent a complete ophthalmological assessment including best corrected visual acuity (BCVA), applanation tonometry, anterior segment slit-lamp evaluation and photography, break-up time (BUT), Schirmer's test, meniscus tear measurement, funduscopy, digital confocal laser-scanning microscope (LSM) (HRT III Rostock Cornea Module; Heidelberg Engineering $\mathrm{GmbH}$, Heidelberg, Germany), optic nerve disk analysis (HRT III Rostock Glaucoma Module; Heidelberg Engineering $\mathrm{GmbH}$ ) and visual field examination (Humphrey Field analyzer, model HFA II-750; Zeiss Humphrey Systems, Dublin, CA, USA), with the Swedish Interactive Threshold Algorithm (SITA) Standard 30-2 strategy. 
Follow-up visits were scheduled at 6 and 12 months after enrollment and all the examinations were repeated at each visit.

Moreover, during the follow-up period, IOP measurements were performed not only at 6 and 12 months, but also when required by the glaucoma specialist, to ensure a correct IOP control and proper adherence to the therapy.

Enrolled patients were randomized at a $1: 1$ ratio for monotherapy with either bimatoprost $0.01 \%$ ophthalmic solution or bimatoprost $0.03 \%$ ophthalmic solution (oncedaily, between 2000 and $2100 \mathrm{~h}$ ) for 1 year. The randomization sequence was computer generated.

The primary goal was to analyze and compare changes in global clinical score (pruritus, stinging/burning, blurred vision, sticky eye sensation, eye dryness sensation, and foreign body sensation) between the two treatment cohorts.

The secondary goal was to report changes in functional parameters (Schirmer's test, BUT, and meniscus tear), anterior segment photography (conjunctival hyperemia), and IVCM findings (corneal epithelium and endothelium cells, goblet cells and conjunctival epithelium) between the two treatment cohorts.

Inclusion criteria were topical monotherapy with bimatoprost $0.03 \%$ ophthalmic solution since at least 1 year, perimetric POAG, pseudoexfoliation, and pigmentary glaucoma, age $>18$ years and willingness to return in the 12 months following enrollment for scheduled visits.

Exclusion criteria were known allergy or sensitivity to the study medication or its components, previous other glaucoma topical therapies, contact lens wear, previous or current use of any other ocular medication, including artificial tear therapy, previous intraocular surgery (except cataract surgery at least 180 days before inclusion), IOP $>21 \mathrm{~mm} \mathrm{Hg}$ or visual field loss progression requiring other therapies, angle closure glaucoma, neovascular glaucoma, uveitic glaucoma, active clinical ocular infection requiring treatment and significant co-morbid diseases that could interfere with the interpretation of the study data, history of recurrent seasonal allergies within the past 2 years, history of severe ocular trauma or refractive surgery at any time, and uncontrolled systemic inflammatory disease.

\section{Clinical assessment parameters}

Global clinical score ranged from 0 (absence of symptoms) to 18 (maximum severity of symptoms) corresponding to the sum of individual parameters that were scored on a four-grade scale of none (0), mild (1), moderate (2), and severe (3).
Conjunctival hyperemia was scored using a standardized photographic scale derived from McMonnies grading (1-6).

\section{In vivo confocal microscopy}

We investigated the microscopic epithelial features of the superior bulbar conjunctiva and the microscopic epithelial and endothelial features of the central cornea.

IVCM analysis was performed by a single operator (LM) who selected and evaluated six images (from $\sim 40$ images), and the results were averaged by a second IVCM operator (SL).

Sequential images $400 \times 400 \mathrm{~mm}$ in size derived from manual frames were acquired at the superficial layer of the superior bulbar conjunctival epithelium $(0-10 \mathrm{~mm})$, $2 \mathrm{~mm}$ from the limbus in downward gaze.

All images with goblet cells identifiable were selected and encoded randomly. Three images were selected to count the number of goblet cells (Cell Count Software, Heidelberg Engineering $\mathrm{GmbH}$, integrated in HRT3 device) in manual mode and to calculate the average goblet cell density (GCD). The conjunctival epithelium cellularity was also calculated in the same manner, and the results were expressed as cells per square millimeter (cells $/ \mathrm{mm}^{2}$ ).

The center of the cornea was studied in all examinations and two complete confocal analyses of the entire central cornea were performed for each eye.

\section{Statistical analysis}

Statistical analysis was performed using the GraphPad Prism software package, version 5.0 (GraphPad Software Inc., San Diego, CA, USA). Paired $t$-test and repeated measures ANOVA test were used to calculate changes in global clinical score, conjunctival hyperemia score, and IVCM features during the 12-month follow-up within cohorts and between groups. The level of significance was set at $P<0.05$.

\section{Sample size}

Formal sample size was calculated to assess the change in global clinical score (which was the primary outcome of our study) between the pre- and post-interventional periods, and between groups, if one existed. Treatment difference for the primary criterion was estimated with a two-sided 95\% CI and a 5\% non-inferiority margin.

We assumed a change of $10 \%$ of the maximum possible score (18 points) as clinically relevant, and we therefore estimated $\Delta$ (the difference between post- and pre-interventional global clinical score) at $1.8 \pm 3.0$.

Using $\alpha=0.05$ and $\beta=0.90$, the sample size would enumerate 30 patients per group. 


\section{Results}

Seventy-five glaucoma patients in monotherapy with bimatoprost $0.03 \%$ were pre-enrolled. Fifteen patients were excluded: six due to previously glaucoma surgery, four because of other topical glaucoma medications used before starting with bimatoprost $0.03 \%$ eye drop, three were contact lens wearers and two for concomitant allergic conjunctivitis.

A total of 60 patients (60 eyes) were included in the study. No differences between groups were seen for gender, age, laterality, and lens status $(\mathrm{P}>0.05)$.

Ninety-three percent of patients were diagnosed with glaucoma in both eyes: only one randomized eye was included in the statistical analysis. All the enrolled patients followed the study protocol and no discontinuations were detected.

There were no differences in baseline clinical characteristics and IVMC features between treatment groups $(P>0.05)$ (Table 1$)$.

Global clinical score significantly improved in the bimatoprost $0.01 \%$ group at both follow-up visits $(P<0.001)$ and a statistically significant difference between groups was reported $(P<0.001)$ (Figure 1$)$. Interestingly, the most significant improvements were in stinging/burning $(P<0.001)$, foreign body sensation $(P<0.001)$, and eye dryness sensation $(P=0.006)$.

Scores of each symptom are reported in Table 2.

Conjunctival hyperemia was less frequent and severe in the bimatoprost $0.01 \%$ group at both 6- and 12-month follow-up visits ( $P=0.011$ and $P<0.001$, respectively) (Figure 2). Importantly, the percentage of moderate to severe hyperemia significantly decreased over time in the bimatoprost $0.01 \%$ group (Figure 2).

Meniscus tear, Schirmer's test, and BUT reported an increase in baseline values in the bimatoprost $0.01 \%$ group $(P<0.05)$, with significant differences between groups at each follow-up point $(P<0.05)$.

IVCM showed a statistically significant improvement in GCD in the bimatoprost $0.01 \%$ group: GCD increased from baseline $351.8 \pm 192.3$ to $425.6 \pm 178.5$ cells $/ \mathrm{mm}^{2}$
$\left(P<0.0001 ;\right.$ mean difference $=73.8$ cells $\left./ \mathrm{mm}^{2}\right)$ and to $428.5 \pm 171$ cells $/ \mathrm{mm}^{2}(P<0.0001$; mean difference $=76.7$ cells $/ \mathrm{mm}^{2}$ ) at 6 - and 12 -month follow-ups, respectively (Figure 3). Differences between groups were statistically significant at each follow-up time point $(P<0.001)$ (Figure 3$)$.

No changes were reported for the other IVCM parameters $(P>0.05)$.

Also, mean IOP and BCVA did not change significantly in either group or between groups at each follow-up $(P>0.05)$

Visual field parameters (MD, PSD, and VFI) were relatively stable in both groups $(P>0.05)$.

HRT III Glaucoma Module showed a relatively stable Cup Disk ratio in both groups and no differences between groups were detected $(P>0.05)$.

No patients needed to change the therapy in the follow-up time because of uncompensated IOP, and no corneal toxicity, such as corneal erosions or punctate keratitis, has been revealed in either group.

\section{Discussion}

The problem of potentially toxic glaucoma treatments is receiving much more attention owing to the increased number of patients in the world. The lifespan of treatments requires not only good efficacy, but also

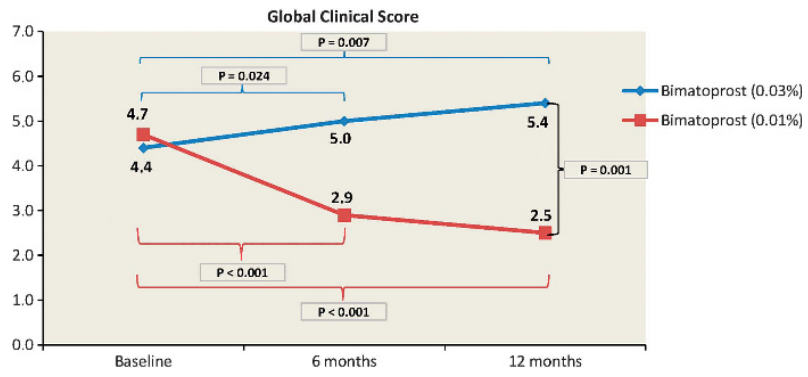

Figure 1 Global clinical score.

Table 1 Baseline characteristics

\begin{tabular}{lccc}
\hline & Bimatoprost 0.03\% & Bimatoprost 0.01\% & P-value \\
\hline Global clinical score $(n \pm \mathrm{SD})$ & $4.4 \pm 3.2$ & $4.7 \pm 3.8$ & 0.911 \\
Conjunctival hyperemia $(n \pm \mathrm{SD})$ & $1.9 \pm 1.6$ & $2.1 \pm 1.9$ & 0.709 \\
Meniscus tear $(n \pm \mathrm{SD})$ & $0.2 \pm 0.0$ & $0.2 \pm 0.0$ & 0.905 \\
Schirmer's test $(\mathrm{s} \pm \mathrm{SD})$ & $10.1 \pm 5.0$ & $9.8 \pm 5.5$ & 0.593 \\
Break-up time $(\mathrm{s} \pm \mathrm{SD})$ & $9.8 \pm 4.7$ & $7775.9 \pm 2.3$ & 0.593 \\
Corneal epithelium density $(n \pm \mathrm{SD})$ & $7430.8 \pm 2155.0$ & 0.469 \\
Corneal endothelium density $(n \pm \mathrm{SD})$ & $2917.0 \pm 956.1$ & $2913.9 \pm 979.2$ & 0.976 \\
Conjunctival epithelium density $(n \pm \mathrm{SD})$ & $4266.8 \pm 1656.0$ & $4357.9 \pm 1618$ & 0.813 \\
Goblet cell density $(n \pm \mathrm{SD})$ & $353.9 \pm 179.6$ & $351.8 \pm 192.3$ & 0.894 \\
IOP $(\mathrm{mm}$ Hg $\pm \mathrm{SD})$ & $14.30 \pm 2.00$ & $14.13 \pm 1.68$ & 0.687 \\
\hline
\end{tabular}


Table 2 Symptoms score

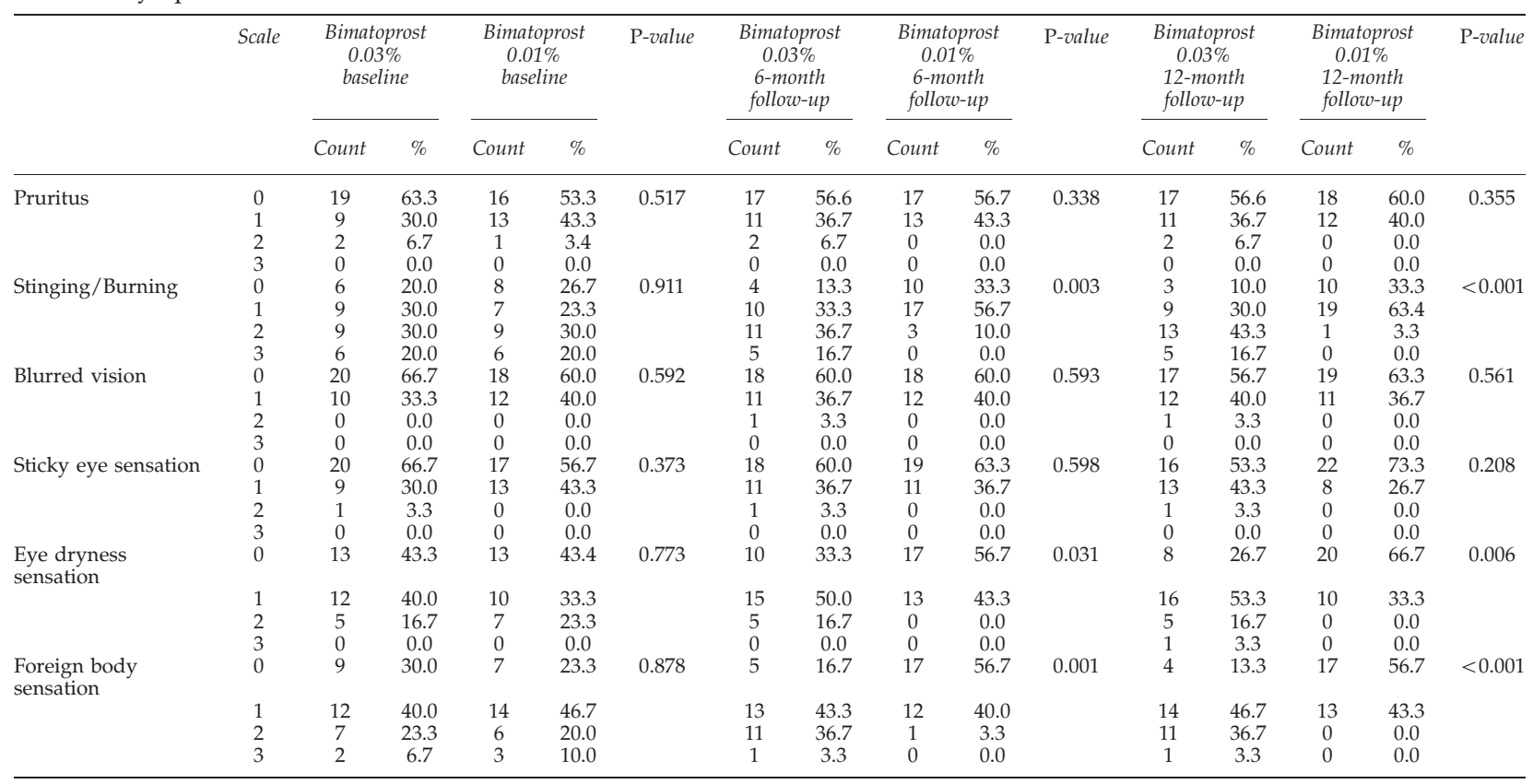

safety, good tolerability, and optimal compliance for patients.

Previous clinical trials have demonstrated that bimatoprost $0.03 \%$ ophthalmic solution is safe and effective in lowering IOP. ${ }^{13-17}$ Nevertheless, side effects can result in patient discontinuation from treatment or additional office visits. ${ }^{29}$ Therefore, comparing clinical signs and symptoms and IVCM findings between two similar glaucoma groups in monotherapy with one of the commercially available bimatoprost formulations ( 0.03 or $0.01 \%$ ) may give important information regarding the role of the drug and BAK for the safety of antiglaucoma eye drop chronic instillation.

Both bimatoprost formulations have been well tolerated by patients because no discontinuations have been detected, although the strict inclusion criteria (only glaucoma patients in monotherapy with bimatoprost $0.03 \%$ since at least 1 year) might have affected this outcome. Indeed, the inclusion of patients who tolerated the treatment during the period of at least 1 year could have influenced the good general tolerability observed to the tested drug, despite BAK or drug concentration changes.

Moreover, the exclusion of patient with concomitant ocular surface disease or current use of artificial therapy could mean that the present study investigated the safety of bimatoprost and BAK only in the glaucomatous eyes with relatively 'healthy ocular surface' compared with the average glaucoma patient being treated. However, the authors have considered it appropriate to select these patients because the non-homogeneous use of different artificial tears or the presence of ocular surface diseases at different stages could have significantly affected the results of the study.

In addition, given that the intervals between followups are rather long, it is likely that some of the patients may not adhered to the medication during the follow-up period. This is an important issue because possible poor compliance may erroneously show improvement in an adverse outcome profile. A practical way to completely overcome this problem does not exist. However, to limit this possible source of bias, we also evaluated the glaucoma progression analysis, which was similar between groups at each follow-up $(P>0.05)$.

Finally, a weakness of this study is represented by its open-label design and this aspect could theoretically affect the subjective score of the symptoms. However, the fact that our results closely parallel to those of an important double-masked clinical trial ${ }^{12}$ suggests that this may have not greatly impacted the results.

Despite these biases, our results suggest a better local tolerance of bimatoprost $0.01 \%$ compared with $0.03 \%$ formulation, with less subjective symptoms (especially stinging/burning, foreign body sensation, and eye dryness sensation) and conjunctival hyperemia.

This conclusion may be supported by evidence of an increase in GCD in the bimatoprost $0.01 \%$ group reported by IVCM. Goblet cells of the conjunctiva are terminally differentiated cells secreting mucins and antibacterial peptides that have an important role in maintaining the health of the cornea. ${ }^{30}$ The absence or even reduction of mucus in the tear, because of reduced conjunctival GCD, 

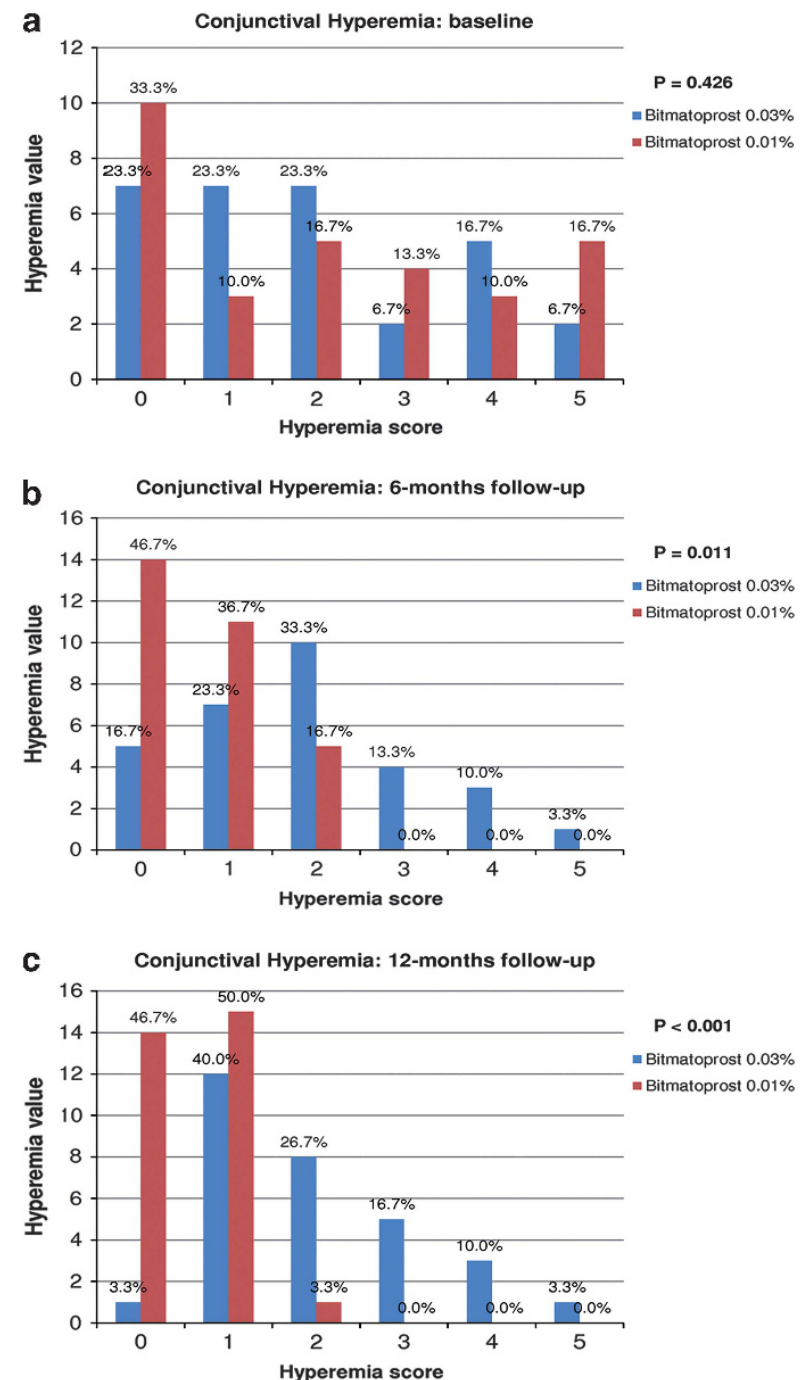

Figure 2 Conjunctival hyperemia at (a) baseline, (b) 6-months follow up and (c) 12-months follow up.

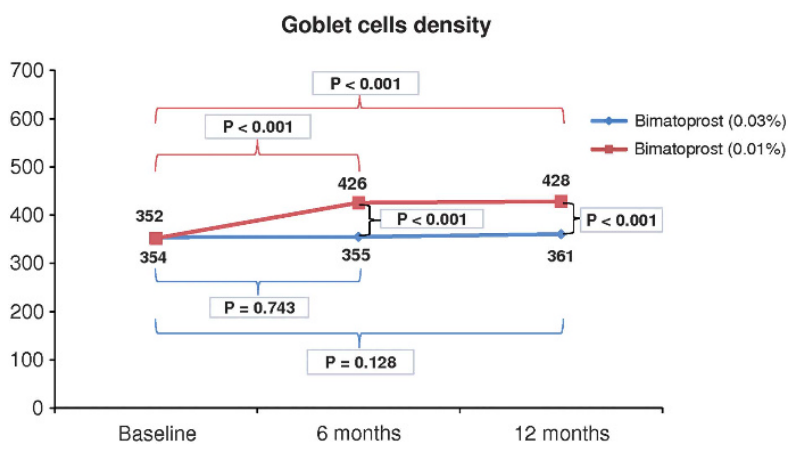

Figure 3 Goblet cell density.

compromises the proper dispersion of pre-corneal tear film, leading to keratoconjunctivitis sicca. ${ }^{31,32}$

Conjunctival GCD in healthy subjects ranges from 380 to 430 cells $/ \mathrm{mm}^{2} .^{33-35}$ In our patient groups, baseline
GCD was under the value of healthy subjects (about 350 cells $/ \mathrm{mm}^{2}$ in both groups) because of at least 1 year of bimatoprost $0.03 \%$ instillation. After shifting the therapy to $0.01 \%$ eye drop formulation, GCD returned within the healthy subjects values $(425.5 \pm 178.5$ and $428.5 \pm 171$ cells $/ \mathrm{mm}^{2}$ at 6 - and 12 -month follow-ups, respectively). Restoring a normal value of the GCD may explain the improvement in functional parameters and symptoms.

Strangely, in the bimatoprost $0.03 \%$ group, GCD remains relatively stable, without further reduction despite continued therapy. Trend analysis of GCD in these patients before the enrollment is not known because in The Glaucoma Unit of Pisa University IVCM of the conjunctiva is not a standard procedure for the management of glaucoma patients. However, to explain the lack of further loss of goblet cells in the bimatoprost $0.03 \%$ group, the authors hypothesize that the reduction in GCD can occurred in the first period of bimatoprost $0.03 \%$ therapy (before the enrollment), reaching a steady state that is less influenced by the duration of the therapy.

BAK and ophthalmic solutions containing BAK may be responsible for toxic effects on cultured cells ${ }^{36-37}$ and for damage to the ocular surface in the rabbit model system, ${ }^{38-40}$ but recent well-controlled phase III clinical studies have not demonstrated injurious effects of BAK in study populations of patients with glaucoma or OHT. ${ }^{41-43}$ In particular, Hamacher et $a l^{41}$ in a pharmacodynamics analysis did not find statistically significant differences between BAK-free and BAKcontaining formulations in the incidence of ocular adverse events comparing preservative-free tafluprost with tafluprost containing $0.01 \%$ BAK. Also, in the work of Gross et $a l^{42}$, travoprost BAK free and travoprost preserved with BAK showed no differences in the safety and Lewis et al ${ }^{43}$ have demonstrated no differences in the incidence of side ocular effects, comparing travoprost $0.004 \%$ containing $0.015 \%$ BAK with travoprost $0.004 \%$ BAK free.

Bimatoprost $0.01 \%$ contains the same $0.02 \%$ concentration of BAK as latanoprost $0.005 \%$, which has been used safely in glaucoma treatment for many years. ${ }^{44,45}$ Indeed, in a work of Townley et al ${ }^{46}$, symptoms of ocular discomfort were significantly lower in eyes treated with latanoprost $0.005 \%$ preserved with $0.02 \%$ BAK than in eyes treated with travoprost preserved with a different preservative.

Kats et $a l^{12}$ reported that the severity of conjunctival hyperemia was decreased in the bimatoprost $0.01 \%$ group compared with the bimatoprost $0.03 \%$ group. Our results agree with those of Kats, showing a significant reduction in the severity of conjuctival hyperemia in the bimatoprost $0.01 \%$ group. 
In conclusion, the results of this randomized, prospective, parallel-group, open-label, cohort study suggest that the concentration of the BAK seems to be less influential than active drug concentration in the tolerability of chronic therapy with bimatoprost eye drop.

The development of an alternative formulation with higher concentration of BAK and lower of active drug might prove to be beneficial also for patients having concomitant ocular surface disease and for those with sensitivity to this drug. Further studies aimed at confirming the tolerability of this new bimatoprost formulation in patients with ocular surface disease are needed.

\section{Summary}

\section{What was known before}

- BAK in ophthalmic solutions may cause ocular toxicity, as demonstrated by numerous in vitro and in vivo studies.

- Bimatoprost $0.01 \%$ is equivalent to bimatoprost $0.03 \%$ in lowering IOP throughout 12 months of treatment with less associated incidence of side effects such as conjuctival hyperemia.

\section{What this study adds}

- The concentration of the benzalkonium chloride seems to be less influential than active drug concentration in the tolerability of chronic therapy with bimatoprost eye drop.

\section{Conflict of interest}

The authors declare no conflict of interest.

\section{References}

1 Resnikoff S, Pascolini D, Etya'ale D, Kocur I, Pararajasegaram R, Pokharel GP et al. Global data on visual impairment in the year 2002. Bull World Health Organ 2004; 82: 844-851.

2 Quigley HA. Glaucoma. Lancet 2001; 377: 1367-1377.

3 Tung JD, Tafreshi A, Weinreb RN, Slight JR, Slight JR, Medeiros FA, Liu JH. Twenty-four-hour effects of bimatoprost $0.01 \%$ monotherapy on intraocular pressure and ocular perfusion pressure.. BMJ Open 2012; 2(4):pii e001106.

4 Figus M, Lazzeri S, Nardi M, Bartolomei MP, Ferreras A, Fogagnolo P. Short-term changes in the optic nerve head and visual field after trabeculectomy. Eye 2011; 25: 1057-1063.

5 Chauhan BC, Mikelberg FS, Balaszi AG, LeBlanc RP, Lesk MR, Trope GE et al. Canadian Glaucoma Study 2: risk factors for the progression of open-angle glaucoma. Arch Ophthalmol 2008; 126: 1030-1036.

6 Heijl A, Leske MC, Bengtsson B, Hyman L, Bengtsson B, Hussein $\mathrm{M}$ et al. Reduction of intraocular pressure and glaucoma progression: results from the Early Manifest Glaucoma trial. Arch Ophthalmol 2002; 120: 1268-1279.
7 Maier PC, Funk J, Schwarzer G, Antes G, Falck-Ytter YT. Treatment of ocular hypertension and open angle glaucoma: meta-analysis of randomized controlled trials. BMJ 2005; 331: 134.

8 Van der Walk R, Webers CA, Schouten JS, Zeegers MP, Hendrikse F, Prins $\mathrm{MH}$ et al. Intraocular pressure-lowering effects of all commonly used glaucoma drugs: a metaanalysis of randomized clinical trials. Ophthalmology 2005; 112: $1177-1185$.

9 Bean GW, Camras CB. Commercially available prostaglandin analogs for the reduction of intraocular pressure: similarities and differences. Surv Ophthalmol 2008; 53: S69-S84.

10 Sharif NA, Kelly CR, Williams GW. Bimatoprost (Lumigan ${ }^{\mathbb{R}}$ ) is an agonist at the cloned human ocular FP prostaglandin receptor: real-time FLIPR-based intracellular $\mathrm{Ca}(2+)$ mobilization studies. Prostaglandins Leukot Essent Fatty Acids 2003; 68: 27-33.

11 Sharif NA, Williams GW, Kelly CR. Bimatoprost and its free acid are prostaglandin FP receptor agonists. Eur J Pharmacol 2001; 432: 211-213.

12 Kats LJ, Cohen JS, Batoosingh AL, Felix C, Shu V, Schiffman RM. Twelve-month, randomized, controlled trial of bimatoprost $0.01 \%, 0.0125 \%$, and $0.03 \%$ in patients with glaucoma or ocular hypertension. Am J Opthalmol 2010; 149: 661-671.

13 Higginbotham EJ, Schuman JS, Goldberg I, Gross RL, VanDenburgh AM, Chen $\mathrm{K}$ et al. One-year, randomized study comparing bimatoprost and timolol in glaucoma and ocular hypertension. Arch Ophthalmol 2002; 120: 1286-1293.

14 Cohen JS, Gross RL, Cheetham JK, VanDenburgh AM, Bernstein P, Whitcup SM. Two-year double-msked comparison of bimatoprost with timolol in patients with glaucoma or ocular hypertension. Surv Ophthalmol 2004; 49: S45-S52.

15 Williams RD, Cohen JS, Gross RL, Liu CC, Safyan E, Batoosingh AL et al. Long-term efficacy and safety of bimatoprost for intraocular pressure lowering in glaucoma and ocular hypertension: year 4. Br J Ophthalmol 2008; 92: 1387-1392.

16 How AC, Kumar RS, Chen YM, Su DH, Gao H, Oen FT et al. A randomized crossover study comparing bimatoprost and latanoprost in subjects with primary angle closure glaucoma. Br J Ophthalmol 2009; 93: 782-786.

17 Cantor LB, Hoop J, Morgan L, Wudunn D, Catoira Y. Bimatoprost-Travoprost Study Group. Intraocular pressure-lowering efficacy of bimatoprost $0.03 \%$ and travoprost $0.004 \%$ in patients with glaucoma or ocular hypertension. Br J Ophthalmol 2006; 90: 1370-1373.

18 Astin M, Stjernschantz J, Selèn G. Role of nitric oxide in PGF2 alpha-induced ocular hyperemia. Exp Eye Res 1994; 59: 401-407.

19 Chen J, Dinh T, Woodward DF, Holland M, Yuan YD, Lin TH et al. Bimatoprost: mechanism of ocular surface hyperemia associated with topical therapy. Cardiovasc Drug Rev 2005; 23: 231-246.

20 Sherwood M, Brandt J. Six-month comparison of bimatoprost once-daily and twice-daily with timolol twice-daily in patients with elevated intraocular pressure. Surv Ophthalmol 2001; 45: S361-S368.

21 Hollò G. The side effects of the prostaglandin analogues. Exper Opin Drug Saf 2007; 6: 45-52. 
22 Ogundele $\mathrm{AB}, \mathrm{Li} \mathrm{G}$, Ellis JJ. Impact of topical bimatoprost $0.01 \%$ and bimatoprost $0.03 \%$ on conjunctival irritation in rabbits. Clin Ophthalmol 2010; 18: 77-80.

23 Nakamura T, Yamada M, Teshima M, Nakashima M, To H, Ichikawa $\mathrm{N}$ et al. Electrophysiological characterization of tight junctional pathway of rabbit cornea treated with ophthalmic ingredients. Biol Pharm Bull 2007; 30: 2360-2364.

24 McCarey B, Edelhauser H. In vivo corneal epithelial permeability following treatment with prostaglandin analogs [correction of analoges] with or without benzalkonium chloride. J Ocul Pharmacol Ther 2007; 23: 445-451.

25 Epstein SP, Chen D, Asbell PA. Evaluation of biomarkers of inflammation in response to benzalkonium chloride on corneal and conjunctival epithelial cells. J Ocul Pharmacol Ther 2009; 25: 415-424.

26 De Saint JM, Brignole F, Bringuier AF, Bauchet A, Feldmann G, Baudouin C. Effects of benzalkonium chloride on growth and survival of Chang conjunctival cells. Invest Ophthalmol Vis Sci 1999; 40: 619-630.

27 Debbash C, Pisella PJ, De Saint JM, Rat P, Warnet JM, Baudouin C. Mitochondrial activity and glutathione injury in apoptosis induced by unpreserved and preserved beta-blockers on Chang conjuctival cells. Invest Ophthalmol Vis Sci 2001; 42: 2525-2533.

28 Ciancaglini M, Carpineto P, Agnifili L, Nubile M, Fasanella V, Lanzini M et al. An in vivo confocal microscopy and impression cytology analysis of preserved and unpreserved levobunolol-induced conjuctival changes. Eur J Ophthalmol 2008; 18: 400-407.

29 Schwartz GF, Reardon G. A cost-effectiveness comparison of bimatoprost versus latanoprost in patients with glaucoma or ocular hypertension. Surv Ophthalmol 2004; 49: 621-623.

30 Pajoohesh-Ganji A, Pal-Ghosh S, Tadvalkar G, Stepp MA. Corneal goblet cells and their niche: implications for corneal stem cell deficiency. Stem Cells 2012; 30: 2032-2043.

31 Taylor HR. The biological effects of UV-B on the eye. Photochem Photobiol 1989; 50: 489-492.

32 Tiffany JM. Tears in health and disease. Eye 2003; 17: 923-926.

33 Calonge M, Diebold Y, Saez V, Enríquez de Salamanca A, García-Vázquez C, Corrales RM et al. Impression cytology of the ocular surface: a review. Exp Eye Res 2004; 78: 457-472.

34 Prabhasawat P, Tseng SCG. Impression cytology study of epithelial phenotype of ocular surface reconstructed by preserved human amniotic membrane. Arch Ophthalmol 1997; 115: 1360-1367.

35 Nelson DJ. Impression cytology. Cornea 1988; 7: 71-81.

36 Pisella PJ, Debbasch C, Hamard P, Creuzot-Garcher C, Rat $\mathrm{P}$, Brignole $\mathrm{F}$ et al. Conjunctival proinflammatory and proapoptotic effects of latanoprost and preserved and unpreserved timolol: an ex vivo and in vitro study. Invest Ophthalmol Vis Sci 2004; 45: 1360-1368.

37 Guenoun JM, Baudouin C, Rat P, Pauly A, Pauly A, Warnet JM, Brignole-Baudouin F. In vitro study of inflammatory potential and toxicity profile of latanoprost, travoprost, and bimatoprost in conjunctiva-derived epithelial cells. Invest Ophthalmol Vis Sci 2005; 46: 2444-2450.

38 Whitson JT, Cavanagh HD, Lakshman N, Petroll WM. Assessment of corneal epithelial integrity after acute exposure to ocular hypotensive agents preserved with and without benzalkonium chloride. Adv Ther 2006; 23: 663-671.

39 Liang H, Baudouin C, Pauly A, Brignole-Baudouin F. Conjunctival and corneal reactions in rabbits following short- and repeated exposure to preservative-free tafluprost, commercially available latanoprost and $0.02 \%$ benzalkonium chloride. Br J Ophthalmol 2008; 92: 1275-1282.

40 Kahook MY, Noecker RJ. Comparison of corneal and conjunctival changes after dosing of travoprost preserved with sofZia, latanoprost with $0.02 \%$ benzalkonium chloride, and preservative-free artificial tears. Cornea 2008; 27: 339-343.

41 Hamacher T, Airaksinen J, Saarela V, Liinamaa MJ, Richter U, Ropo A. Efficacy and safety levels of preserved and preservative- free tafluprost are equivalent in patients with glaucoma or ocular hypertension: results from a pharmacodynamics analysis. Acta Ophthalmol Suppl (Oxf) 2008; 242: 14-19.

42 Gross RL, Peace JH, Smith SE, Walters TR, Dubiner HB, Weiss MJ et al. Duration of IOP reduction with travoprost BAK-free solution. J Glaucoma 2008; 17: 217-222.

43 Lewis RA, Katz GJ, Weiss MJ, Landry TA, Dickerson JE, James JE et al. Travoprost $0.004 \%$ with and without benzalkonium chloride: a comparison of safety and efficacy. J Glaucoma 2007; 16: 98-103.

44 Camras CB, Alm A, Watson P, Stjernschantz J. Latanoprost, a prostaglandin analog, for glaucoma therapy. Efficacy and safety after 1 year of treatment in 198 patients. Latanoprost Study Groups. Ophthalmology 1996; 103: 1916-1924.

45 Goldberg I, Li XY, Selaru P, Paggiarino D. A 5-year, randomized, open-label safety study of latanoprost and usual care in patients with open-angle glaucoma or ocular hypertension. Eur J Ophthalmol 2008; 18: 408-416.

46 Townley JR, Reilly C. Dry eye and irritation comparison of Latanoprost $0.005 \%$ with the preservative benzalkonium chloride (BAC) versus Travaprost $0.004 \%$ without BAC. Invest Ophthalmol Vis Sci 2009; 50: E-Abstract 4651. Available at http://abstracts.iovs.org/cgi/content/ abstract $/ 50 / 5 / 4651$. 